\title{
Proposal of Numerical Model for Airport Pavement Management Purposes
}

\author{
Karen A. Camarena, B. Eng. ${ }^{1}$, Leonardo Flores, M.Sc. ${ }^{1}$ \\ ${ }^{1}$ Universidad Nacional de Ingeniería, Perú, k.camarena.campos@gmail.com, lfloresg@uni.edu.pe
}

\begin{abstract}
This article presents the results of a quantitative investigation with descriptive and correlation scopes, where a database for pavements of a Peruvian airport was elaborated, with the purpose of developing a prediction numerical model of the pavement condition, which relates the pavement condition index (PCI) as a function of time (pavement age).

Given the limitation of the pavement condition historical data and the need of them to know the pavement behavior under specific conditions (climate, traffic, material, among others) a quantitative numerical model is proposed applying Markov chains, calculating the Markov probability transition matrix from a data nonlinear logistic regression numerical process.

Finally, the model validation is presented, which is the main tool of an Airport Pavement Management System (APMS), because it allows pavement status forecasting knowing its current status.

Keywords --Pavement, PCI, APMS, deterioration model, pavement age.
\end{abstract}

\section{INTRODUCTION}

Several factors cause pavement deterioration such as environmental, surface and structural conditions, changes in operational traffic, etc. [8]; in this regard, maintenance and rehabilitation (M\&R) of airport pavements must be carried out in a preventive and programmed way, instead based on immediate needs and without proper planning [7], as is being done in Peru (see Fig. 1); jeopardizing operational safety and without considering the economic resources available.

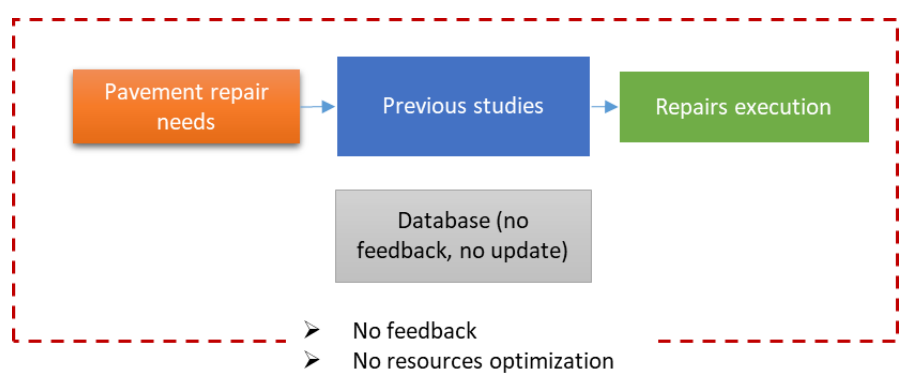

Fig. 1 M\&R without Pavement Management Source: [5]

What is required to guarantee an adequate pavements service level of the airports movement area of Peru, during its life cycle and the years it can be extended?

To implement an APMS, whose prediction nume model of pavement condition, the main tool of the syster developed and calibrated for the specific conditions that $\mathrm{c}$ pavement deterioration (operational traffic, environm conditions, etc.).

Digital Object Identifier (DOI): http://dx.doi.org/10.18687/LACCEI2018.1.1.417 ISBN: 978-0-9993443-1-6 ISSN: $2414-6390$

$16^{\text {th }}$ LACCEI International Multi-Conference for Engineering, Education, and Technology: "Innovation in Education and Inclusion", 19-21 July 2018, Lima, Peru.
II. DATABASE

To prepare a database, the pavement construction and inspection background of the main Peruvian airports was reviewed. The Cajamarca Airport runway (flexible pavement) was selected because the amount of information that was compiled, for the development of a practical case.

Fig. 2 shows the pavement inventory and TABLE 1 lists pavement inspections and M\&R history.

a) PAVEMENT NETWORK

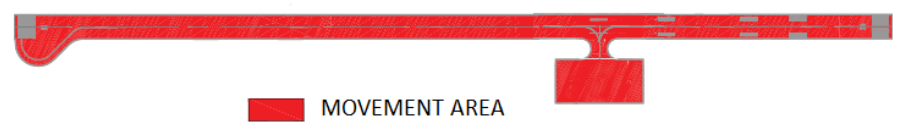

b) PAVEMENT BRANCH

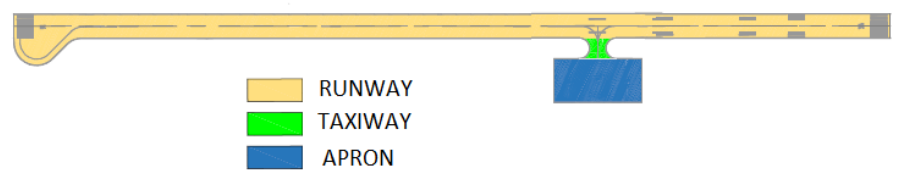

Fig. 2. Cajamarca Airport Pavements

TABLE 1. PCI - CAJAMARCA AIRPORT RUNWAY SOURCE: [5]

\begin{tabular}{|c|c|c|}
\hline Year & Activity & PCI \\
\hline 2003 & Pavement Improvement and expansion & -- \\
2007 & Pavement condition inspection & 91 \\
2013 & Pavement condition inspection & 65 \\
2014 & Corrective maintenance & -- \\
2014 & Pavement condition inspection & 86 \\
2015 & Pavement condition inspection & 82 \\
\hline
\end{tabular}

\section{A. Pavement structure}

The runway PCN is $45 / \mathrm{F} / \mathrm{D} / \mathrm{X} / \mathrm{T}$ and the maximum allowable aircraft type is the Boeing 737 (maximum takeoff weight $=$ $134000 \mathrm{lb})$.

Fig. 3 shows the runway sectorization, based on the structure (material and thickness), construction and M\&R history, and areas where traffic loads are uniform. TABLE 2 describes the

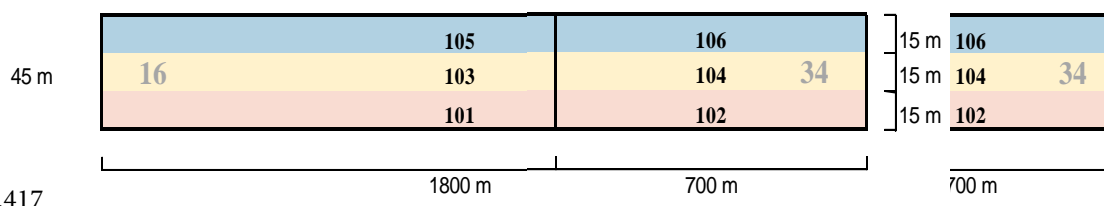

Fig. 3. Sectorization - Cajamarca Airport Runway 
TABLE 2. PCI - CAJAmARCA AirPort Runway 2017 STRUCTURE SOURCE: [5]

\begin{tabular}{|c|c|c|c|c|c|c|}
\hline \multirow{2}{*}{ Rolling surface } & \multicolumn{6}{|c|}{ Section } \\
\cline { 2 - 8 } & $\mathbf{1 0 1}$ & $\mathbf{1 0 2}$ & $\mathbf{1 0 3}$ & $\mathbf{1 0 4}$ & $\mathbf{1 0 5}$ & $\mathbf{1 0 6}$ \\
\hline Asphalt concrete $(\mathrm{cm})$ & 12.5 & 12.5 & 12.5 & 12.5 & 12.5 & 12.5 \\
\hline Base $(\mathrm{cm})$ & 51 & 51 & 51 & 56 & 56 & 56 \\
\hline Sub base $(\mathrm{cm})$ & 39 & 39 & 39 & 20 & 20 & 20 \\
\hline
\end{tabular}

\section{B. Traffic Data}

The traffic data is necessary to analyze the possible pavement deterioration causes and to propose appropriate $M \& R$ alternatives considering the decrease or increase of traffic loads repetitions, or a constant transit in time [7].

TABle 3. Operations Projection 2017-2034 SOURCE: [5]

\begin{tabular}{|c|c|c|}
\hline Year & $\begin{array}{c}\mathbf{N}^{\circ} \text { annual } \\
\text { average } \\
\text { operations }\end{array}$ & $\begin{array}{c}\mathbf{N}^{\circ} \text { annual } \\
\text { average } \\
\text { departures }\end{array}$ \\
\hline 2017 & 4245 & 2123 \\
\hline 2018 & 4542 & 2271 \\
\hline 2019 & 4860 & 2430 \\
\hline 2020 & 5201 & 2601 \\
\hline 2021 & 5565 & 2783 \\
\hline 2022 & 5943 & 2972 \\
\hline 2023 & 6335 & 3168 \\
\hline 2024 & 6741 & 3371 \\
\hline 2025 & 7159 & 3580 \\
\hline 2026 & 7588 & 3794 \\
\hline 2027 & 8021 & 4011 \\
\hline 2028 & 8454 & 4227 \\
\hline 2029 & 8894 & 4447 \\
\hline 2030 & 9320 & 4660 \\
\hline 2031 & 9740 & 4870 \\
\hline 2032 & 10139 & 5070 \\
\hline 2033 & 10535 & 5268 \\
\hline 2034 & 10945 & 5473 \\
\hline
\end{tabular}

\section{Pavement Condition}

The pavement condition data is a fundamental component of an APMS and requires an objective, systematic and repetitive evaluation process [7]. The ASTM D5340, qualify the pavement condition with the PCI, whose value corresponds between 0 and 100, see TABLE 4 . The called standard stablish that a pavement begins its life cycle with perfect conditions $(\mathrm{PCI}=100)$ and after being subjected to service cycles, that cause pavement deterioration can reach a collapsed state $(\mathrm{PCI}=0)[1]$.

The PCI values shown in TABLE 5, are the sample units data process result that contains each section; the area of each sample units is $450 \mathrm{~m} 2 \pm 150 \mathrm{~m} 2$ [1].
TABLE 4. PCI RATING SCALE. SOURCE: [1]

\begin{tabular}{|cc|c|}
\hline \multicolumn{3}{|c|}{ PCI rating scale } \\
\hline $86-100$ & GOOD \\
\hline $71-85$ & SATISFACTORY \\
\hline $56-70$ & ACEPTABLE \\
\hline $41-$ & -55 & POOR \\
\hline $26-$ & 40 & VERY POOR \\
\hline $11-$ & -25 & SERIOUS \\
\hline $0-$ & 10 & FAILED \\
\hline
\end{tabular}

TABLE 5. PCI SUMMARY BY SECTION SOURCE: [5]

\begin{tabular}{|c|c|c|c|}
\hline Section & $\begin{array}{c}\text { Inspection } \\
\text { date }\end{array}$ & PCI & Sort \\
\hline \multirow[t]{4}{*}{101} & 2007 & 91 & RWY \\
\hline & 2013 & 68 & RWY \\
\hline & 2014 & 82 & RWY \\
\hline & 2015 & 82 & RWY \\
\hline \multirow[t]{4}{*}{102} & 2007 & 91 & RWY \\
\hline & 2013 & 66 & RWY \\
\hline & 2014 & 81 & RWY \\
\hline & 2015 & 88 & RWY \\
\hline \multirow[t]{4}{*}{103} & 2007 & 89 & RWY \\
\hline & 2013 & 64 & RWY \\
\hline & 2014 & 88 & RWY \\
\hline & 2015 & 84 & RWY \\
\hline \multirow[t]{4}{*}{104} & 2007 & 90 & RWY \\
\hline & 2013 & 61 & RWY \\
\hline & 2014 & 83 & RWY \\
\hline & 2015 & 92 & RWY \\
\hline \multirow[t]{4}{*}{105} & 2007 & 91 & RWY \\
\hline & 2013 & 63 & RWY \\
\hline & 2014 & 84 & RWY \\
\hline & 2015 & 82 & RWY \\
\hline \multirow[t]{4}{*}{106} & 2007 & 91 & RWY \\
\hline & 2013 & 63 & RWY \\
\hline & 2014 & 83 & RWY \\
\hline & 2015 & 85 & RWY \\
\hline
\end{tabular}

\section{DATA ANALYSIS}

To ensure the construction of an appropriate deterioration model, the defective information must be previously separate (PCI analysis of each SU). Errors can be committed during the data collection (pavement inspection) or by entering the values into the database [12].

Consequently, a data preselection process is presented to identify the defective data (Fig. 4) and, a descriptive statistics graphic method to separate the outliers (Fig. 5).

16 $^{\text {th }}$ LACCEI International Multi-Conference for Engineering, Education, and Technology: "Innovation in Education and Inclusion", 19-21 July 2018, Lima, Peru. 


\subsection{Data Preselection}

Before identify the "errors", the sample units corresponding PCI values, must be sort by pavement section, time since the pavement construction or the last reconstruction (age), and finally identify the $M \& R$ activities done [12].

To identify the defective data, the following criteria must be considered [3], [1]:

- Sequential data is compared, among which there were no interventions.

- The pavement condition cannot fall more than one state, it means, PCI difference cannot be more than 20 points.

- The PCI cannot increase unless an intervention is performed. If this is the case, if the increase is greater than 5 points, invest the values, otherwise, equal the PCI values. - The PCI range is from 0 to 100 .

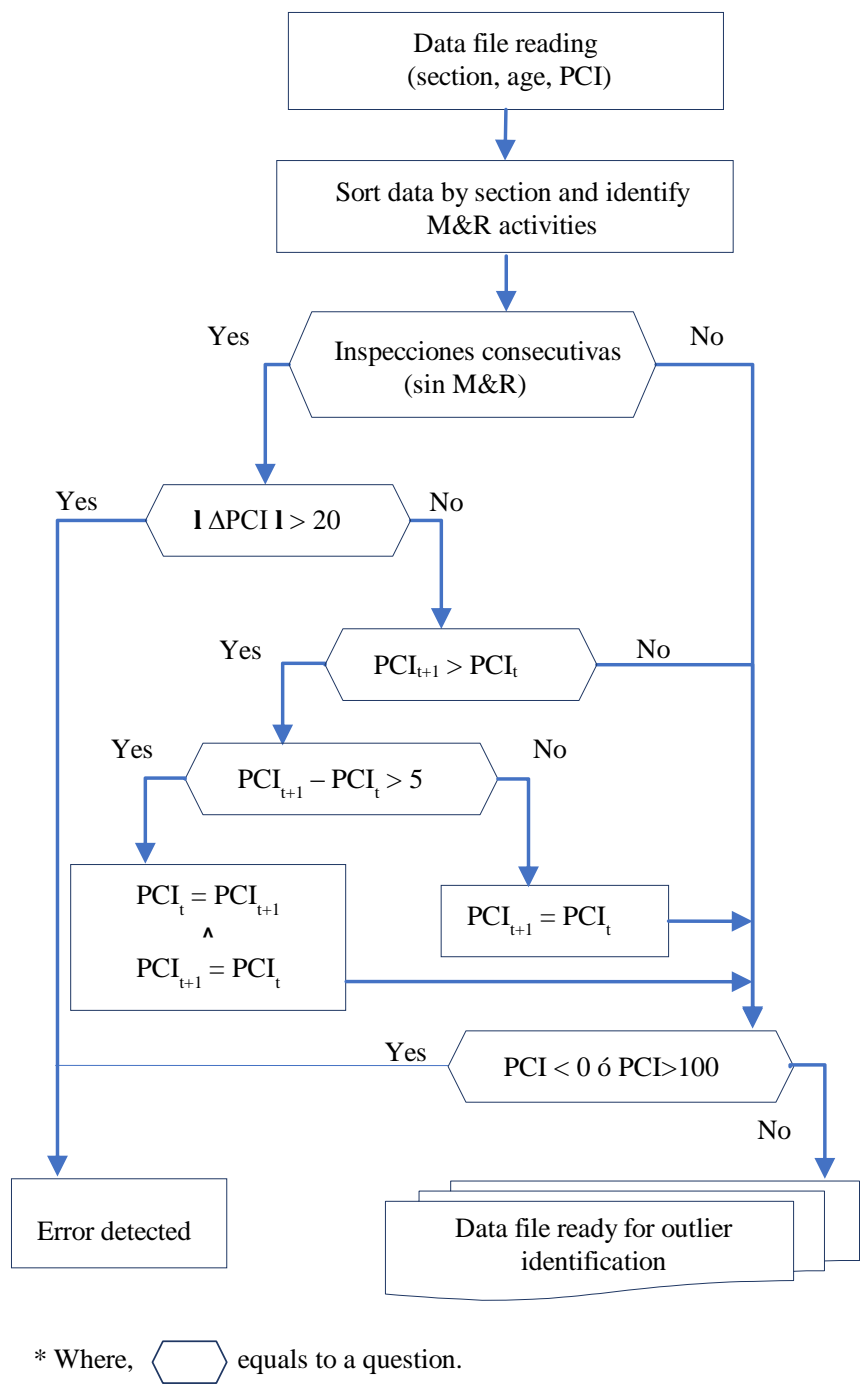

Fig. 4. Data preselection process flow diagram Source:[12], [2], [1]

\subsection{Outlier identification}

A descriptive statistics graphic method called "box plot" will be used. The box plot is used to identify the outliers, because even a single outlier drastically affects the mean and the standard deviation of the data set. A box plot is based on the following summary of quantities [4]:

$$
\begin{array}{rll}
\mathrm{X}_{\text {mín }} & \text { : min. value } & \mathrm{Q} 3 \text { : upper quartil } \\
\mathrm{Q} 1 & \text { : lower quartile } & \mathrm{X}_{\text {máx }} \text { : max. value } \\
\mathrm{Q} 2 & \text { : mean } & f_{s}: \mathrm{Q} \text { 3-Q1 }
\end{array}
$$

Any observation out of range "Q1-1.5fs" to "Q3+1.5fs", is an outlier, that must be separated [4].

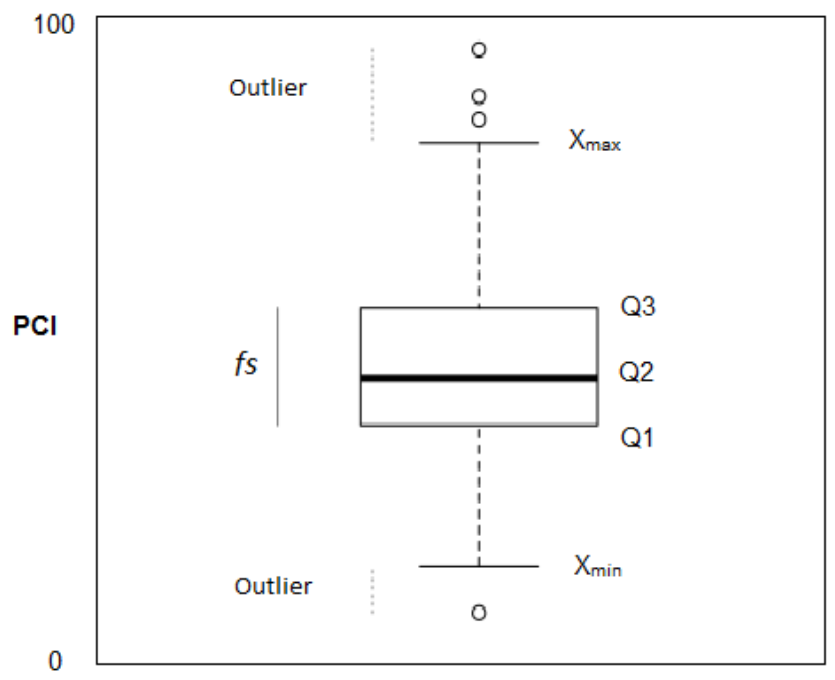

Fig. 5. Box Plot-PCI outlier Source: [4]

\section{NUMERICAL PREDICTION MODEL}

The deterioration models or also called prediction models are an essential tool for the APMS. They are relative to the influence of the pavements state indicators and are used to predict when the interventions on the pavement will be necessary and the budget required for its preservation [7].

The pavement network preservation planning is not a static process; therefore, the APMS are based on probability as a tool to determine the future pavement condition [18].

The deterioration model development must be take the following steps [12]: (Fig. 6)

1. Recovery and storage of data by pavements family.

2. Preselection to identify obvious errors.

3. Identification of outliers.

4. Model development.

$16^{\text {th }}$ LACCEI International Multi-Conference for Engineering, Education, and Technology: "Innovation in Education and Inclusion", 19-21 July 2018, Lima, Peru. 


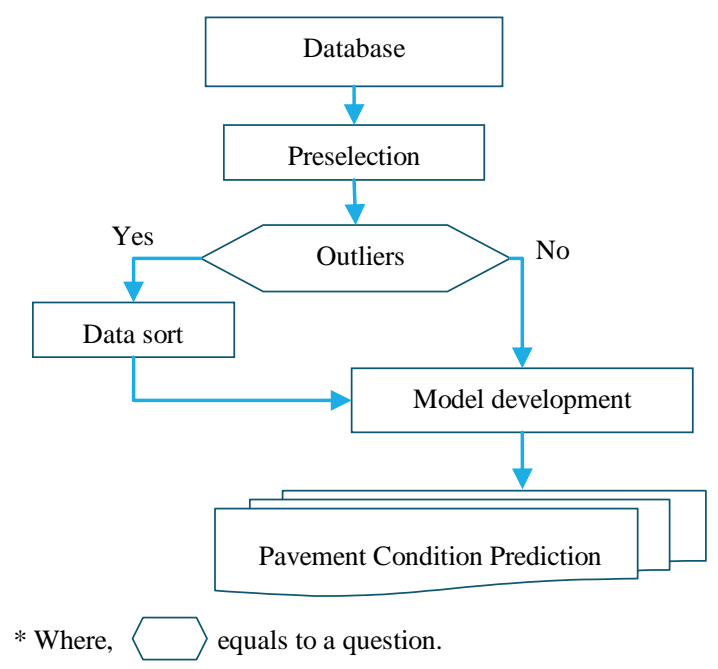

Fig. 6. Model development process flow diagram Source: [12]

\subsection{Markov Chains}

The pavement future condition is estimated as a function of probability for the set of possible states that could arise [14].

Knowing the preceding state or the pavement probabilistically state, the Markov chains can be used to predict the next state, again probabilistically, for as many periods of time as desired.[15].

\subsection{Prediction Numerical Model Applying Markov Chains}

A pavement begins its life cycle in almost perfect conditions and is then subjected to service cycles that cause deterioration of the pavement condition. The extrapolation of the Markov process curve represents the future pavement behavior and allows a dynamic programming, to produce $M \& R$ optimal strategies [3].

For the development of this model, the Markov process states correspond to different pavement deterioration levels defined in the PCI qualification. The PCI range (from 0 to 100) is divided into ten "states" of 10 interval points, as illustrated in the Table 6.

Table 6. PAVEMENT CONDITION - MARKOV PROCESS. SOURCE:[3]

\begin{tabular}{|c|cccccccccc|}
\hline Condition & A & B & C & D & E & F & G & H & I & J \\
\hline PCI Range & $100-91$ & $90-81$ & $80-71$ & $70-61$ & $60-51$ & $50-41$ & $40-31$ & $30-21$ & $20 .-11$ & $10-0$ \\
\hline
\end{tabular}

Equation (1) illustrates the state vector for a given service cycle.

State vector $(\bar{E})$ for service cicle "i":

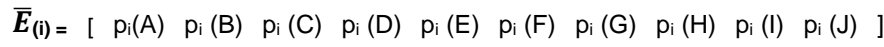

Where, $\operatorname{pi}(\mathrm{X})$ is the probability that pavement is in the condition "X" in the service cycle "i", the "state vector" $\left(\overline{\boldsymbol{E}}_{(\mathbf{i})}\right)$ indicates the probability that a pavement section is in each of the ten states in a year of service (i) and a "service cycle" lasts for one year, at which time the pavement is subjected to a determined climate and traffic.

In the pavements management it is assumed that all sections of the pavement are in the "A" state (PCI of 90 to 100) at the age of zero years (service cycle "0"), resulting a state vector [15]:

$$
\overline{\boldsymbol{E}}_{(0)=}\left[\begin{array}{llllllllllll}
1 & 0 & 0 & 0 & 0 & 0 & 0 & 0 & 0 & 0 & ]
\end{array}\right]
$$

To model the way pavement deteriorates over time, it is necessary to identify the transition probability matrix (TPM).

It is assumed that the pavement condition cannot fall more than one state (10 points) during a service cycle. In addition, the pavement may remain in its condition or deteriorate and move to the next state in one year. Consequently, the TPM has the following form:

$$
\overline{\mathbf{P}}=\left[\begin{array}{cccccccccc}
\mathrm{p}_{\mathrm{AA}} & \mathrm{p}_{\mathrm{AB}} & 0 & 0 & 0 & 0 & 0 & 0 & 0 & 0 \\
0 & \mathrm{p}_{\mathrm{BB}} & \mathrm{p}_{\mathrm{BC}} & 0 & 0 & 0 & 0 & 0 & 0 & 0 \\
0 & 0 & \mathrm{p}_{\mathrm{CC}} & \mathrm{p}_{\mathrm{CD}} & 0 & 0 & 0 & 0 & 0 & 0 \\
0 & 0 & 0 & \mathrm{p}_{\mathrm{DD}} & \mathrm{p}_{\mathrm{DE}} & 0 & 0 & 0 & 0 & 0 \\
0 & 0 & 0 & 0 & \mathrm{p}_{\mathrm{EE}} & \mathrm{p}_{\mathrm{EF}} & 0 & 0 & 0 & 0 \\
0 & 0 & 0 & 0 & 0 & \mathrm{p}_{\mathrm{FF}} & \mathrm{p}_{\mathrm{FG}} & 0 & 0 & 0 \\
0 & 0 & 0 & 0 & 0 & 0 & \mathrm{p}_{\mathrm{GG}} & \mathrm{p}_{\mathrm{GH}} & 0 & 0 \\
0 & 0 & 0 & 0 & 0 & 0 & 0 & \mathrm{p}_{\mathrm{HH}} & \mathrm{p}_{\mathrm{HI}} & 0 \\
0 & 0 & 0 & 0 & 0 & 0 & 0 & 0 & \mathrm{p}_{\mathrm{II}} & \mathrm{p}_{\mathrm{IJ}} \\
0 & 0 & 0 & 0 & 0 & 0 & 0 & 0 & 0 & 1
\end{array}\right]
$$

Where, $p i j$ is the probability that the pavement in state $i$, changes to the state $j$ between service cycles $t$ and $t+1$.

The value 1 in the last row of the TPM corresponds to the state " $\mathrm{j}$ " (PCI from 0 to 10 ), which indicates that the pavement condition cannot pass from this state, unless an intervention is made on the pavement.

The state vector for any year of service is obtained by multiplying the initial state vector by the TPM, as illustrated in (4).

$$
\begin{aligned}
& \overline{\boldsymbol{E}}_{(1)}=\overline{\boldsymbol{E}}_{(0)} \times \overline{\mathbf{P}} \\
& \overline{\boldsymbol{E}}_{(2)}=\overline{\boldsymbol{E}}_{(1)} \times \overline{\mathbf{P}}=\overline{\boldsymbol{E}}_{(0)} \times \overline{\mathbf{P}}^{2} \\
& \cdot \\
& \overline{\boldsymbol{E}}_{(\mathrm{t})}=\overline{\boldsymbol{E}}_{(\mathrm{t}-1)} \times \overline{\mathbf{P}}=\overline{\boldsymbol{E}}_{(0)} \times \overline{\mathbf{P}}^{\mathrm{t}}
\end{aligned}
$$

With this process, if the transition matrix can be estimated, the pavement status for any service cycle can be predicted. The TPM can be determined based on expert criteria or historical data if available, through non-linear regression, where the

16 ${ }^{\text {th }}$ LACCEI International Multi-Conference for Engineering, Education, and Technology: "Innovation in Education and Inclusion", 19-21 July 2018, Lima, Peru. 
objective is to minimize the difference between the PCI obtained as a function of time (product of the regression) and the value predicted (using the Markov chain) for a given service cycle [3].

It is important to mention that, it was rejected to elaborate the TPM based on the "expert's criteria", since with the historical data regression method it is possible to obtain a better approximation of the data generated to the original data[15]; also, various investigations for the construction of master curves that represent pavement deterioration as [13] y [17], has demonstrated that the best function for its representation is the logistic function.

\subsection{Logistic Regression}

Logistic regression means supposing that $\mathrm{p}(\mathrm{x})$ is related to $\mathrm{x}$ through the logistic function (5). Whereas $\mathrm{p}(\mathrm{x})$ is a probability and, therefore, it must be between 0 and 1 , while $\beta 0+\beta 1 \mathrm{x}$ does not need to be in this range [4].

$$
p(x)=\frac{e^{\beta 0+\beta 1 x}}{1+e^{\beta 0+\beta 1 x}}
$$

A pavement begins its life cycle in "almost perfect conditions" (trend to PCI value $=100$ ) and, after being subjected to service cycles and fulfilling its useful life, the PCI has a tendency to value " 0 ". In addition, it is worth mentioning that an increase in the value of the PCI over time is not possible, unless an intervention is made on the pavement. The representation of the characteristics mentioned above is guaranteed with a logistic regression, which creates an "S" shaped curve with maximum and minimum restrictions[3]. Whose graphic representation is the following:

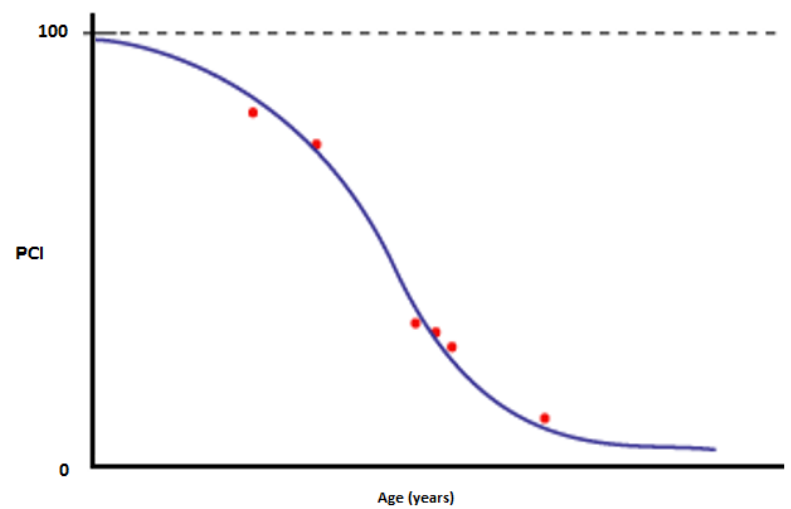

Fig. 7. Logistic function - Graphic representation (PCI vs Time) Source: [4],[14]

The mathematical representation is (6):

$$
\operatorname{PCI}(t)=100 \times \frac{e^{\beta 0+\beta 1 t}}{1+e^{\beta 0+\beta 1 t}}
$$

Where $\beta 0$ y $\beta 1$ are constants, and the independent variable (time).

To adjust the logistic regression to the sample data of the sample, it is necessary to determine the parameters with a process that is complicated to detail. However, statistical software packages do this if requested [4].

Consequently, Table 8 is presented, which contains the data analyzed and worked with the generalized reduced gradient nonlinear regression algorithm, included in the Excel Solver tool; which is used to optimize an objective function, which in this case will be the minimum difference between the PCI obtained from the PCI observed [15].

Table 7. DATA - GENERALIZED REDUCED GRADIENT NONLINEAR

\begin{tabular}{|c|c|c|c|c|c|c|}
\hline Section & $\begin{array}{c}\text { Inspection } \\
\text { date }\end{array}$ & $\mathrm{PCl}$ & Age & $\begin{array}{c}\text { Corrected } \\
\text { age }\end{array}$ & $\mathrm{PCl}(\mathrm{t})$ & $\begin{array}{c}\min \\
\mathrm{IPCl}(\mathrm{t})- \\
\mathrm{PCI} \mid\end{array}$ \\
\hline \multirow[t]{4}{*}{101} & 2007 & 91 & 4 & 4 & 91 & 0 \\
\hline & 2013 & 68 & 10 & 10 & 64 & 4 \\
\hline & 2014 & 83 & 0 & 6 & 86 & 3 \\
\hline & 2015 & 81 & 1 & 7 & 82 & 1 \\
\hline \multirow[t]{4}{*}{102} & 2007 & 91 & 4 & 4 & 91 & 0 \\
\hline & 2013 & 66 & 10 & 10 & 64 & 2 \\
\hline & 2014 & 87 & 0 & 6 & 86 & 1 \\
\hline & 2015 & 81 & 1 & 7 & 82 & 1 \\
\hline \multirow[t]{4}{*}{103} & 2007 & 89 & 4 & 4 & 91 & 2 \\
\hline & 2013 & 64 & 10 & 10 & 64 & 0 \\
\hline & 2014 & 89 & 0 & 6 & 86 & 3 \\
\hline & 2015 & 82 & 1 & 7 & 82 & 0 \\
\hline \multirow[t]{4}{*}{104} & 2007 & 90 & 4 & 4 & 91 & 1 \\
\hline & 2013 & 61 & 10 & 10 & 64 & 3 \\
\hline & 2014 & 91 & 0 & 6 & 86 & 5 \\
\hline & 2015 & 83 & 1 & 7 & 82 & 1 \\
\hline \multirow[t]{4}{*}{105} & 2007 & 91 & 4 & 4 & 91 & 0 \\
\hline & 2013 & 63 & 10 & 10 & 64 & 1 \\
\hline & 2014 & 83 & 0 & 6 & 86 & 3 \\
\hline & 2015 & 82 & 1 & 7 & 82 & 0 \\
\hline \multirow[t]{4}{*}{106} & 2007 & 91 & 4 & 4 & 91 & 0 \\
\hline & 2013 & 63 & 10 & 10 & 64 & 1 \\
\hline & 2014 & 83 & 0 & 6 & 86 & 3 \\
\hline & 2015 & 81 & 1 & 7 & 82 & 1 \\
\hline
\end{tabular}
REGRESSION ALGORITHM

Where:

Age: Inspection year - construction year or last intervention Age corrected: Age + Correction factor (if intervention was identified)

PCI : PCI inspection

PCI (t): see (6)

$\min I \mathrm{PCl}(\mathrm{t})-\mathrm{PCI} \mathrm{I} \quad$ : Objective function 
Resulting the Correction Factor equal to 6 years for the inspections carried out after the maintenance of the year 2014, and (7) as a representation of the pavement behavior.

$$
P C I(t)=100 \times \frac{e^{3.4-0.3 t}}{1+e^{3.4-0.3 t}}
$$

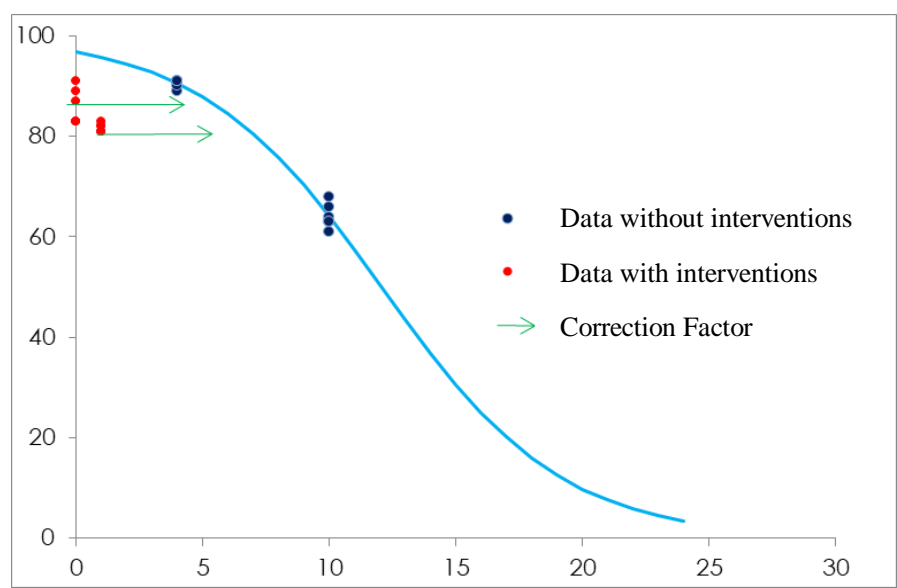

Fig. 8. PCI vs Age - Cajamarca airport runway

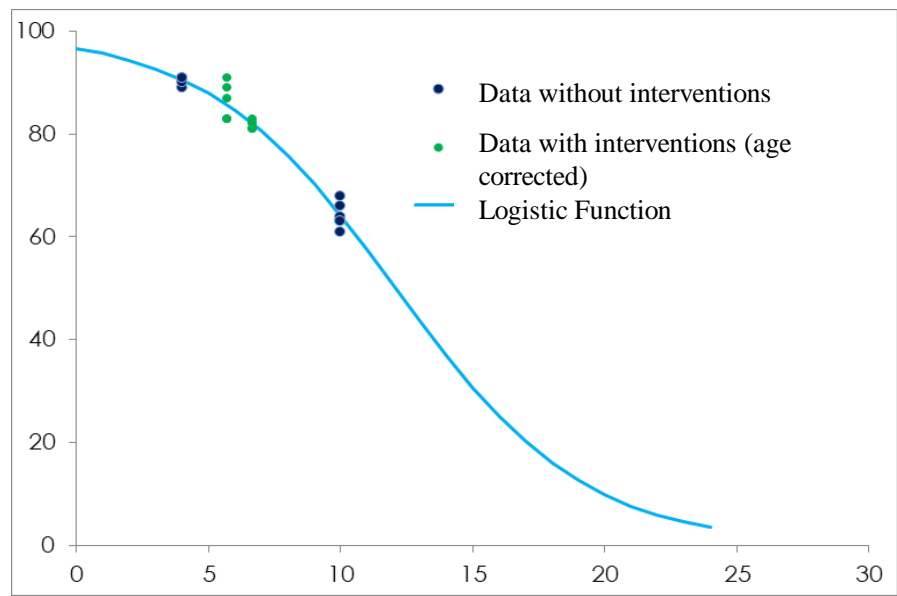

Fig. 9. PCI vs Age (corrected)- Cajamarca airport runway

\subsection{Numerical Prediction Model Calibration}

With the generalized reduced gradient nonlinear regression algorithm, included in the Excel Solver tool, having as objective function the minimum difference between the obtained PCI and the logistic function (7) and PCI obtained with the Markov chain and, as a restriction, the sum of the probability that the pavement is maintained or that it passes to the next state is equal to $1(p i+\mathrm{pi}+1=1)[15]$; the TPM shown below is obtained.

$$
\overline{\mathbf{P}}=\left[\begin{array}{cccccccccc}
81 \% & 19 \% & 0 & 0 & 0 & 0 & 0 & 0 & 0 & 0 \\
0 & 71 \% & 29 \% & 0 & 0 & 0 & 0 & 0 & 0 & 0 \\
0 & 0 & 56 \% & 44 \% & 0 & 0 & 0 & 0 & 0 & 0 \\
0 & 0 & 0 & 37 \% & 63 \% & 0 & 0 & 0 & 0 & 0 \\
0 & 0 & 0 & 0 & 5 \% & 95 \% & 0 & 0 & 0 & 0 \\
0 & 0 & 0 & 0 & 0 & 0 \% & 100 \% & 0 & 0 & 0 \\
0 & 0 & 0 & 0 & 0 & 0 & 0 \% & 100 \% & 0 & 0 \\
0 & 0 & 0 & 0 & 0 & 0 & 0 & 0 \% & 100 \% & 0 \\
0 & 0 & 0 & 0 & 0 & 0 & 0 & 0 & 0 \% & 100 \% \\
0 & 0 & 0 & 0 & 0 & 0 & 0 & 0 & 0 & 100 \%
\end{array}\right]
$$

Replacing (2) and (8) in (4), table 8 is obtained:

\begin{tabular}{|c|c|c|c|c|c|c|c|c|c|c|c|}
\hline \multirow{2}{*}{$\begin{array}{c}\text { Age } \\
\text { (years) }\end{array}$} & \multicolumn{10}{|c|}{ State vector $(\%)$} & \multirow{2}{*}{ PCI } \\
\hline & $\mathbf{A}$ & B & $\mathbf{C}$ & D & $\mathbf{E}$ & $\mathbf{F}$ & $\mathbf{G}$ & $\mathbf{H}$ & $\mathbf{I}$ & $\mathbf{J}$ & \\
\hline 0 & 100.0 & 0.0 & 0.0 & 0.0 & 0.0 & 0.0 & 0.0 & 0.0 & 0.0 & 0.0 & 100 \\
\hline 1 & 81.3 & 18.7 & 0.0 & 0.0 & 0.0 & 0.0 & 0.0 & 0.0 & 0.0 & 0.0 & 98 \\
\hline 2 & 66.1 & 28.4 & 5.5 & 0.0 & 0.0 & 0.0 & 0.0 & 0.0 & 0.0 & 0.0 & 96 \\
\hline 3 & 53.7 & 32.4 & 11.4 & 2.4 & 0.0 & 0.0 & 0.0 & 0.0 & 0.0 & 0.0 & 94 \\
\hline 4 & 43.7 & 33.0 & 15.9 & 6.0 & 1.5 & 0.0 & 0.0 & 0.0 & 0.0 & 0.0 & 91 \\
\hline 5 & 35.5 & 31.5 & 18.5 & 9.3 & 3.8 & 1.4 & 0.0 & 0.0 & 0.0 & 0.0 & 88 \\
\hline 6 & 28.9 & 28.9 & 19.5 & 11.7 & 6.0 & 3.6 & 1.4 & 0.0 & 0.0 & 0.0 & 85 \\
\hline 7 & 23.5 & 25.8 & 19.3 & 13.0 & 7.6 & 5.7 & 3.6 & 1.4 & 0.0 & 0.0 & 81 \\
\hline 8 & 19.1 & 22.6 & 18.3 & 13.4 & 8.6 & 7.2 & 5.7 & 3.6 & 1.4 & 0.0 & 76 \\
\hline 9 & 15.5 & 19.6 & 16.8 & 13.1 & 8.9 & 8.1 & 7.2 & 5.7 & 3.6 & 1.4 & 71 \\
\hline 10 & 12.6 & 16.7 & 15.1 & 12.4 & 8.7 & 8.4 & 8.1 & 7.2 & 5.7 & 5.1 & 65 \\
\hline 11 & 10.3 & 14.2 & 13.3 & 11.3 & 8.2 & 8.2 & 8.4 & 8.1 & 7.2 & 10.7 & 59 \\
\hline 12 & 8.3 & 11.9 & 11.6 & 10.1 & 7.5 & 7.8 & 8.2 & 8.4 & 8.1 & 18.0 & 53 \\
\hline 13 & 6.8 & 10.0 & 9.9 & 8.9 & 6.7 & 7.1 & 7.8 & 8.3 & 8.4 & 26.1 & 47 \\
\hline 14 & 5.5 & 8.3 & 8.5 & 7.7 & 5.9 & 6.4 & 7.1 & 7.8 & 8.2 & 34.5 & 42 \\
\hline 15 & 4.5 & 6.9 & 7.1 & 6.6 & 5.2 & 5.6 & 6.4 & 7.2 & 7.8 & 42.7 & 37 \\
\hline 16 & 3.6 & 5.7 & 6.0 & 5.6 & 4.4 & 4.9 & 5.6 & 6.4 & 7.1 & 50.5 & 33 \\
\hline 17 & 3.0 & 4.7 & 5.0 & 4.8 & 3.8 & 4.2 & 4.9 & 5.6 & 6.4 & 57.6 & 30 \\
\hline 18 & 2.4 & 3.9 & 4.2 & 4.0 & 3.2 & 3.6 & 4.2 & 4.9 & 5.6 & 64.0 & 26 \\
\hline 19 & 2.0 & 3.2 & 3.5 & 3.3 & 2.7 & 3.0 & 3.6 & 4.2 & 4.9 & 69.7 & 24 \\
\hline 20 & 1.6 & 2.6 & 2.9 & 2.8 & 2.2 & 2.5 & 3.0 & 3.6 & 4.2 & 74.5 & 21 \\
\hline
\end{tabular}

Table 8. NUMERICAL MODEL STATE VECTORS AND PCI

With Table 8 data (Age and PCI), it is presented the quantitative numerical model graph that represents the pavement behavior with characteristics and similar conditions to the Cajamarca Airport runway (Fig. 10), where the PCI range for its state is shown in Table 6.

$16^{\text {th }}$ LACCEI International Multi-Conference for Engineering, Education, and Technology: "Innovation in Education and Inclusion", 19-21 July 2018, Lima, Peru. 


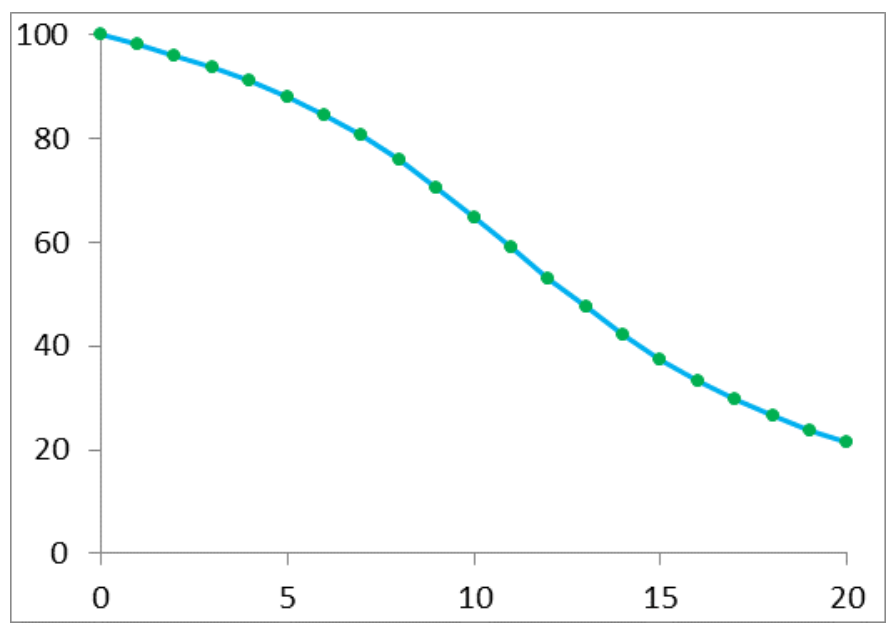

Fig. 10. PCI vs Age - Numerical model state vectors and PCI

\subsection{Model Validation}

TABLE 1 shows the PCI inspection results that will be use to model validation.

The Cajamarca airport runway was improvement and expanded in 2003, year that we will take as age " 0 " (service cycle " 0 ").

Between 2003 - 2007 no intervention was made on the pavements, because of this, the model will be validated with the 2007 data (age 4 years) $\mathrm{PCI}=91$.

Replacing in (2), (8) y $\mathrm{t}=4$ years in (4):

$$
\left.\overline{\boldsymbol{E}}_{(4)=[} \begin{array}{lllllllllll}
43.7 \% & 33.0 \% & 15.9 \% & 6.0 \% & 1.5 \% & 0 & 0 & 0 & 0 & 0
\end{array}\right]
$$

Then the calculation of the PCI for service cycle 4 results:

PCI $\left(\overline{\boldsymbol{E}}_{(4)}\right)=43.7 \%(100)+33.0 \%(90)+15.9 \%(80)+6.0 \%(70)+$ $1.5 \%(60)+0 \%(50)+0 \%(40)+0 \%(30)+0 \%(20)+0 \%(10)=91$

Comparing PCI for service cycle 4 and PCI obtained from field inspection 2007:

$$
\operatorname{PCI}\left(\overline{\boldsymbol{E}}_{(4)}\right)=91=\operatorname{PCI}_{(2007)}=91 \quad \text { OK }
$$

Analogously the PCI for the service cycle 10 and the PCI obtained from the 2013 field inspection is compared:

$$
\operatorname{PCI}\left(\overline{\boldsymbol{E}}_{(10)}\right)=65=\mathrm{PCI}_{(2013)}=65 \quad \text { OK }
$$

\subsection{Prediction Numerical Model role in an APMS}

An APMS needs to be capable of predicting current and future pavement condition. Condition predictions are necessary to analyze different pavement interventions alternatives and develop an optimum multi-year M\&R plan [7]. In this regard, the Prediction Numerical Model is the main tool of an APMS [10], as is shown in Fig. 11.

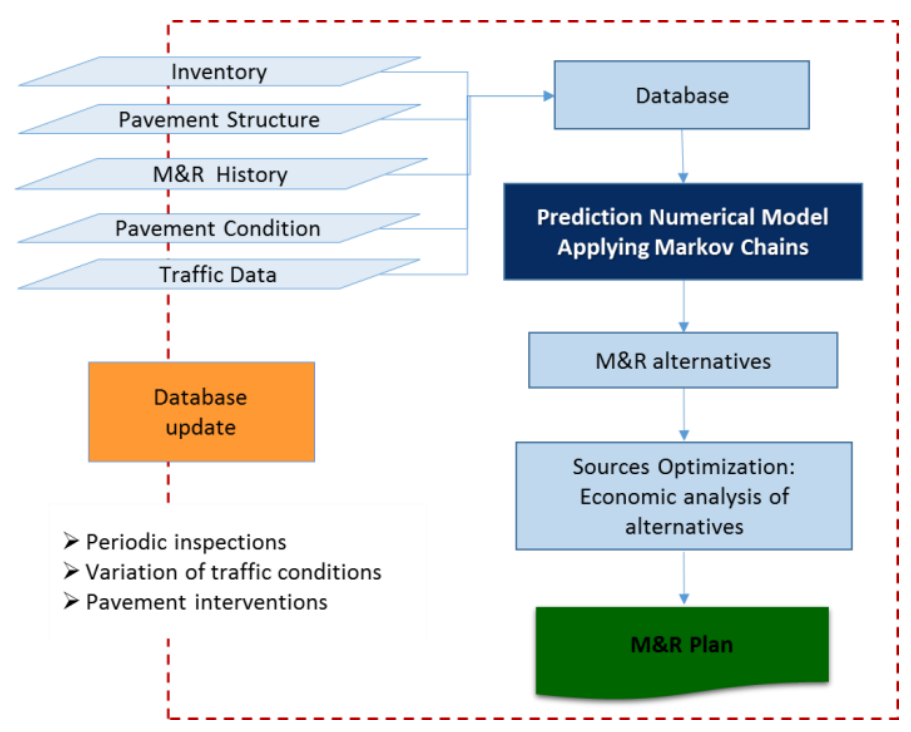

Fig. 11. Airport Pavement Management System (APMS)

\section{CONCLUSIONS}

1. When pavement superficial inspection is carrying out periodically, the numerical indicator PCI and pavement age (time), continuous quantitative variables, can be correlated with the purpose of obtaining a model that describes and predicts the pavement behavior through time.

2. Instead assume pavement behavior (expert judgment) to determine the TPM, it is concluded is possible to obtain data to calibrate the matrix from the non-linear logistic regression numerical process of the historical data collected. This is validated when there are consistent values of deterioration when calculating values obtained with the Markov model (forecast) and the Cajamarca airport runway historical data. PCI $(\overline{\boldsymbol{E}}(4))=$ PCI $(2007)=91$ y PCI $(\overline{\boldsymbol{E}}$ $(10))=$ PCI $(2013)=65$.

3. If deterioration models are made, for different circumstances (weather, traffic, material, among others), which the Peruvian airport pavements are in service; the pavement condition prognosis will depend on how the pavement behaves at present (know the current state).

4. An APMS requires a precise and efficient prediction model, given that pavement interventions programming is based on the state forecasts of the model (see Fig. 11), so the use of the Markov model is adequate. 


\section{REFERENCES}

[1] American Society for Testing and Materials, "Standard Test Method for Airport Pavement Condition Index Surveys", ASTM D5340-12, Pensilvania, 2013.

[2] Butt Abbas, Shahin Mohamed, Feighan Kieran y Carpenter Samuel, "Pavement Performance Prediction Model Using the Markov Process", Transportation Research Record 1123, Illinois, 1987.

[3] Butt Abbas, Shahin Mohamed, Carpenter Samuel y Carnahan James, "Application of Markov Process to Pavement Management Systems at Network Level", 3rd International Conference on Managing Pavements, Illinois, 1994.

[4] Devore Jay, "Probabilidad y estadística para ingeniería y ciencias", Sexta edición, Thomson Editores, México, 2005.

[5] Dirección General de Aeronáutica Civil (DGAC), Ministerio de Transportes y Comunicaciones (MTC), Solicitud de acceso a la información pública T-269907-2017, Lima, Perú, 2017.

[6] Federal Aviation Administration - U.S. Department of Transportation, "Airport Pavement Design and Evaluation", Advisory Circular No 150/5320-6E, Washington D.C., 2009.

[7] Federal Aviation Administration - U.S. Department of Transportation, "Airport Pavement Management Program (PMP)", Advisory Circular No 150/5380-7B, Washington D.C., 2014.

[8] Federal Aviation Administration - U.S. Department of Transportation, "Guidelines and Procedures for Maintenance of Airport Pavements", Advisory Circular No 150/5380-6C, Washington D.C., 2014.

[9] Freeman Thomas, Borowiec Jeffrey, Wilson Bryan, Arabali Poura y Sakhaeifar Maryam, "Pavement Maintenance Guidelines for General Aviation Airport Management", Airport Cooperative Research Program Report 159, Washington D.C., 2016.

[10]George K.P., Rajagopal A.S. y Lim L.K., "Models for Predicting Pavement Deterioration", Transportation Research Record 1215, Misisipi, 1989.

[11]Hajek Jerry, Hall Jim y Hein David, "Common Airport Pavement Maintenance Practices", Airport Cooperative Research Program Synthesis 22, Washington D.C., 2011.

[12]Nuñez María y Shahin Mohamed, "Pavement Condition Data Analysis and Modeling", Transportation Research Record 1070, Illinois, 1986.

[13]Pellinen Terhi, Witczak Matthew, y Bonaquist Ramon, "Asphalt Mix Master Curve Construction using Sigmoidal Fitting Function with NonLinear Least Squares Optimization Technique", Materials characterization/modeling of pavement systems ASCE, New York, 2003.

[14]Solminihac Hernan, "Gestión de infraestructura vial", Ediciones Universidad Católica de Chile, Chile, 2001.

[15]Solorio José, Márquez Zaydith, Montoya Monserrat, Cárdenas Santa y Hernández Domínguez, "Aplicación de métodos markovianos en el modelado del deterioro de carreteras", Instituto Méxicano del Transporte, Publicación Técnica $N^{\circ} 396$, México, 2014.

[16]Tighe Susan y Covalt Margaret, "Implementation of an airport Pavement Management System", Transportation Research Circular, E-C127, Washington D.C., 2008.

[17]Yusoff Nur, Chailleux Emmanuel y Airey Gordon, "A Comparative Study of the Influence of Shift Factor Equations on Master Curve Construction", International Journal of Pavement Research and Technology, Vol. $4 \mathrm{~N}^{\circ} 6$, Nottingham, 2011.

[18]Zimmerman Kathryn, "Pavement Managment Methodologies to select Projects and Recommend Preservation Treatments", Synthesis of Highway Practice 222, Washington D.C., 1995.

16 $^{\text {th }}$ LACCEI International Multi-Conference for Engineering, Education, and Technology: "Innovation in Education and Inclusion", 19-21 July 2018, Lima, Peru. 